\title{
Characterization of urania vaporization with transpiration coupled thermogravimetry
}

\author{
J.W. McMurray* \\ Materials Science and Technology Division, Oak Ridge National Laboratory, Oak Ridge, TN \\ 37831-6063
}

\section{A B S T R A C T}

Transpiration measurements are very useful for determining equilibrium vapor pressures of materials. However, the traditional technique involves condensing the volatiles entrained in a carrier gas outside of the hot measurement zone. One potential problem is deposition en route to a cooled collector. Thermogravimetric analysis (TGA) can be used to measure in situ mass loss due to vaporization and therefore obviate the need to analyze the entire gas train due to premature plating of vapor species. Therefore, a transpiration coupled TGA technique was used to determine equilibrium pressures of $\mathrm{UO}_{3}$ gas over fluorite structure $\mathrm{UO}_{2+\mathrm{x}}$ and $\mathrm{U}_{3} \mathrm{O}_{8}$ at 1573 and $1773 \mathrm{~K}$. The results are compared to calculations from models and databases in the open literature. This study gives clarity to the thermochemical data for $\mathrm{UO}_{3}$ gas and validates the mass loss transpiration method using thermogravimetry for determining equilibrium vapor pressures of non-stoichiometric oxides.

Keywords: $\mathrm{UO}_{2 \pm x}, \mathrm{UO}_{3}$, uranium, urania, volatilization, oxygen potential, phase equilibrium

This manuscript has been authored by UT-Battelle, LLC under Contract No. DE-AC05OOOR22725 with the U.S. Department of Energy. The United States Government retains and the publisher, by accepting the article for publication, acknowledges that the United States Government retains a non-exclusive, paid-up, irrevocable, world-wide license to publish or reproduce the published form of this manuscript, or allow others to do so, for United States Government purposes. The Department of Energy will provide public access to these results of federally sponsored research in accordance with the DOE Public Access Plan (http://energy.gov/downloads/doe-public-access-plan).

*Corresponding author: Jacob W. McMurray email: mcmurrayjw1@ ornl.gov phone: 865-574-6852 


\section{Introduction}

Urania is used as a conventional light water reactor (LWR) nuclear fuel and is a nonstoichiometric oxide represented by the formula $\mathrm{UO}_{2 \pm \mathrm{x}}$. At high temperatures and large values of $x, \mathrm{UO}_{2+\mathrm{x}}$ volatilizes as $\mathrm{UO}_{3}$ gas. This phenomenon is important for understanding conventional LWR (light water reactor) fuel behavior under severe accident scenarios as pointed out by Olander[1]. A breach of cladding allows pressurized water or steam to contact and oxidize $\mathrm{UO}_{2 \pm \mathrm{x}}$ forming both $\mathrm{UO}_{3}$ and $\mathrm{UO}_{2}(\mathrm{OH})_{2}$ vapors. Knowledge of the thermochemistry of $\mathrm{UO}_{3}$ and $\mathrm{H}_{2} \mathrm{O}$ facilitate determining equilibrium $\mathrm{UO}_{2}(\mathrm{OH})_{2}$ pressures for $\mathrm{UO}_{2 \pm \mathrm{x}}$ in steam from experimentation [2] and allow for a better understanding of fuel response to severe accident conditions. While the behavior of $\mathrm{H}_{2} \mathrm{O}$ is well understood from a computational thermodynamic standpoint, Olander [1] reviewed several studies [3; 4; 5] that gave conflicting calculated $\mathrm{UO}_{3}$ vapor pressures $\left(p_{U_{3}}\right)$ over $\mathrm{U}_{3} \mathrm{O}_{8}$. Further, a literature survey revealed no studies reporting equilibrium $p_{\mathrm{UO}_{3}}$ for fluorite structure $\mathrm{UO}_{2+\mathrm{x}}$. Since $\mathrm{U}$ is a heavy atom, this facilitates characterizing vaporization of $\mathrm{UO}_{2+\mathrm{x}}$ by mass loss determinations. Furthermore, $\mathrm{UO}_{2 \pm \mathrm{x}}$ is nonstoichiometric with the value of $x$ depending critically on the system oxygen partial pressure $\left(p_{O_{2}}\right)$. Therefore, the aim of this effort is to clarify the equilibrium $p_{U O_{3}}$ over $\mathrm{UO}_{2+\mathrm{x}}$ with temperature and $p_{\mathrm{O}_{2}}$ by using a transpiration coupled thermogravimetric analysis (TGA) technique.

\section{Experimental procedure}

Merton and Bell provide an excellent and detailed description of the transpiration method in [6]. In brief, an equilibrium concentration of vapors over a sample is established and entrained in a carrier gas that is then transported to a cold trap. The composition of the resulting condensate is analyzed and the mass $\left(m_{i}\right)$ and equilibrium partial pressures $\left(p_{i}\right)$ of each species $i$ can be determined using Eqn. 1:

$p_{i}=\left(\frac{m_{i} / m_{i}}{v \times t+m_{i} / m w_{i}}\right) \times p_{s y s}$

where $v$ is the carrier gas molar flow rate, $m w_{i}$ is the molecular weight of $i, t$ is time, and $p_{s y s}$ is the system pressure.

Several studies, for example $[7 ; 8 ; 9]$, have shown that thermogravimetry can be used to determine $p_{i}$ given knowledge of the major molecular components of the equilibrium vapor and a sufficiently high $p_{i}$ to effect measurable weight loss. Evidence suggests that $\mathrm{UO}_{3}$ and $\mathrm{O}_{2}$ are the 
dominant gas phase species over $\mathrm{UO}_{2+\mathrm{x}}$ at large $x$ and high temperatures in the $\mathrm{U}-\mathrm{O}$ system $[1 ; 2$; $10 ; 11]$.

These experiments were conducted for either $\mathrm{UO}_{2+\mathrm{x}}$ fluorite structure solutions or $\delta-\mathrm{U}_{3} \mathrm{O}_{8}$. Which phase was present was calculated by minimizing the Gibbs energy of the system under the conditions of the measurement using the Calphad assessment of the U-O binary from [12]. The starting material was Areva $\mathrm{UO}_{2+x}$ powder ( $>99.85$ mass \% uranium oxide) pressed into a cylindrical pellet about $3 \mathrm{~mm}$ in diameter and $5 \mathrm{~mm}$ in height. The specimen was conditioned in $\mathrm{Ar}-4 \% \mathrm{H}_{2}$ at $1623 \mathrm{~K}$ for 12 hours to sinter and fix the stoichiometry to $\mathrm{UO}_{2.000 \pm 0.002}$. Calculated phase diagrams for the U-O binary are presented in Fig. 1.

A Netzsch STA 449 F1 Jupiter® was used for the thermogravimetric analysis. A simplified sketch of the apparatus is shown in Fig. 2. The ID of the carrier gas inlet tubing was $1.753 \mathrm{~mm}$ while that of the outlet is $4.57 \mathrm{~mm}$. These small openings provided enough constriction to limit diffusion out of the reaction chamber, a necessary requirement for a transpiration apparatus [6]. A sample of $\mathrm{UO}_{2+\mathrm{x}}$ weighing $~ 350 \mathrm{mg}$ was placed on a flat alumina plate. Oxygen pressures were fixed with an Environics ${ }^{\circledR}$ Series 2000 Multi-Component Gas Mixer by combing $\mathrm{Ar}-4 \% \mathrm{H}_{2}$ and $\mathrm{Ar}-2 \% \mathrm{O}_{2}$ feed streams in appropriate ratios determined from an equilibrium calculation of the following reaction:

$\mathrm{H}_{2}+1 / 2 \mathrm{O}_{2} \leftrightarrow \mathrm{H}_{2} \mathrm{O}$

The sensitivity of the microbalance used in this work is $\pm 0.002 \mu \mathrm{g}$. Thus, urania begins to volatilize noticeably, from the gravimetric standpoint of this study, at temperatures around 1500 $\mathrm{K}$ and $p_{\mathrm{O}_{2}}>10^{-6}$ atm $(1 \mathrm{~atm}=101,325 \mathrm{~Pa})$.

The experimental procedure used was as follows. The sample was heated to temperature under an $\mathrm{Ar}-4 \% \mathrm{H}_{2}$ flow to maintain the oxygen stoichiometry of 2. Argon- $4 \% \mathrm{H}_{2}$ and $\mathrm{Ar}-2 \% \mathrm{O}_{2}$ combinations were then set to achieve a $\log p_{\mathrm{O}_{2}} / \mathrm{atm}=-3$ and the steady state rate of weight loss was recorded for carrier gas flows between 200 and $35 \mathrm{ml} / \mathrm{min}$. at standard temperature and pressure (STP) at both 1573 and $1773 \mathrm{~K}$. This was done in order to determine proper conditions that sufficiently minimized surface reaction kinetics and diffusion limitations. The results of these two series of preliminary runs are shown in Figs. 3 and 4. The partial pressure of $\mathrm{UO}_{3}$ gas was computed with Eqn. 3 below:

$p_{U O_{3}}=\left(\frac{\dot{m} / m w_{U}}{v+\dot{m} / m w_{U}}\right) \times p_{s y s}$ 
where $\dot{m}$ is rate of mass loss of the $\mathrm{UO}_{2+\mathrm{x}}$ sample and $m w_{U}$ is the molecular weight of $\mathrm{U}$. The measurements were conducted at an elevation, $h$, of about 260 meters above sea level and the laboratory was kept at a nearly constant $298 \mathrm{~K}$ temperature; therefore, $p_{\text {sys }}$ was assumed to be constant at 0.97 atm estimated from the following relation:

$$
p_{\text {sys }}=\left(1-h \times 2.25577 \times 10^{-5}\right)^{5.25588} \text { atm }
$$

While $\mathrm{UO}_{3}$ is volatilizing, the oxygen bound to $\mathrm{U}$ in the $\mathrm{UO}_{3}$ molecule is replaced in the solid $\mathrm{UO}_{2+\mathrm{x}}$ phase since the atmosphere is continuously purged with one of a fixed $p_{\mathrm{O}_{2}}$. This means the net $\dot{m}$ is equivalent to $U$ loss only and therefore Eqn. 3 must be used. Since the integral (reacting) system can be considered $\mathrm{U}-\mathrm{O}-\mathrm{H}$, the $\mathrm{UO}_{2}(\mathrm{OH})_{2}$ oxyhydroxide species will only form in very small relative concentrations due to the low partial pressure of water vapor and high temperature of the measurements [1]. The mass loss from $\mathrm{UO}_{2}(\mathrm{OH})_{2}$ has been documented to be well within experimental error and undetectable by the transpiration technique at similar conditions [2]. From Eqn.17 in [1], the following relation can be derived:

$$
p_{U_{2}(\mathrm{OH})_{2}}=\mathrm{K}_{\mathrm{oxy}} p_{\mathrm{UO}_{3}} p_{\mathrm{H}_{2} \mathrm{O}}
$$

where $p_{\mathrm{UO}_{3}(\mathrm{OH})_{2}}$ is the partial pressure of $\mathrm{UO}_{2}(\mathrm{OH})_{2}$ and $K_{\text {oxy }}$ is the equilibrium constant for the reaction:

$\mathrm{UO}_{3}(\mathrm{~g})+\mathrm{H}_{2} \mathrm{O}(\mathrm{g})=\mathrm{UO}_{2}(\mathrm{OH})_{2}(g)$

Olander reported $K_{\text {oxy }}$ decreases from 0.19 to 0.010 from $1500 \mathrm{~K}$ to $2000 \mathrm{~K}$ in [1]. In this study, the $p_{\mathrm{H}_{2}} \mathrm{O}$ was never higher than $1.6 \times 10^{-2} \mathrm{~atm}$. This means $p_{\mathrm{UO}_{3}(\mathrm{OH})_{2}}$ must be about 3 orders of magnitude or more lower than $p_{U O_{3}}$ under the conditions investigated here.

Figs. 3 and 4 show constant $p_{U O_{3}}$ and linear mass loss versus $v$ that intersects the origin for flows between 35 and $50 \mathrm{ml} / \mathrm{min}$; therefore, any value falling in between these two limits satisfies the requirements for the transpiration technique [6] in this case. A setting of $42.5 \mathrm{ml} / \mathrm{min}$ was selected for use in the remainder of the runs since that flow best represented the average $\mathrm{UO}_{3}$ pressures for the plateau region. These measurement were made at $\log p_{O_{2}} / \mathrm{atm}=-2$ and -1.7 at both 1573 and $1773 \mathrm{~K}$. 


\section{Results}

The experimentally determined $p_{U O_{3}}$ with temperature and $p_{O_{2}}$ in equilibrium with $\mathrm{UO}_{2+\mathrm{x}}$ and $\mathrm{UO}_{2+\mathrm{x}}-\mathrm{U}_{3} \mathrm{O}_{8}$ are given in Table 1 . The uncertainty in the $\log p_{O_{2}} /$ atm settings were determined by estimating the propagation of independent random errors [13] from the gas compositions and flow settings from Table 2. The microbalance drift can be as high as \pm 10 $\mu \mathrm{g} / \mathrm{hr}$ yielding $p_{U O_{3}}$ to an accuracy of $4.03 \times 10^{-7} \mathrm{~atm}$. The uncertainty in the temperature reading is estimated to be $\pm 0.05 \mathrm{~K}$ based on calibration of the thermocouple using melting points for the 5 different metal standards listed in Table 3 .

\section{Discussion}

The reaction that forms $\mathrm{UO}_{3}(\mathrm{~g})$ from $\mathrm{UO}_{2+\mathrm{x}}$ is given as:

$U O_{2}^{S S}+1 / 2 O_{2}=U O_{3}(g)$

where the $U O_{2}^{S S}$ compound is a constituent of the overall $\mathrm{UO}_{2+\mathrm{x}}$ hyperstoichiometric solution phase.

Applying the law of mass action yields

$$
p_{U O_{3}}=K_{e q} a_{U O_{2}} \sqrt{p_{O_{2}} / p_{O_{2}}^{\circ}} \times p_{U O_{3}}^{\circ}
$$

where $a_{U O_{2}}$ is the activity of $U O_{2}^{S S}$. The equilibrium constant, $K_{e q}$, can be represented as:

$K_{e q}=e^{-\left(\frac{{ }^{\circ} G_{U U_{3}(g)}{ }^{\circ}{ }^{\circ} G_{U O_{2}}-1 / 2^{\circ} G_{O_{2}}}{R T}\right)}$

where $R$ is the ideal gas constant and $T$ is temperature.

In Fig. 5, the results from this study, along with one from [2], are plotted against calculated $p_{U O_{3}}$ as a function of $p_{\mathrm{O}_{2}}$ from four different sources. The two relations, the Lindemer and Besmann [14] and Blackburn [3] models, describing the activity of $\mathrm{UO}_{2}$ in $\mathrm{UO}_{2+\mathrm{x}}$ with $p_{O_{2}}$ along with the thermodynamic data used to compute the curves labeled Blackburn [3], Ozrin [5] , and AECL [4] are well described in [1]. The Calphad (Calculation of Phase Diagrams) plot, based on the 
assessment of the U-O system after Guéneau et al. [12], best reproduces the experimentally observed behavior. In [12], the Gibbs energy functions for $\mathrm{UO}_{3}(\mathrm{~g}), \mathrm{O}_{2}$, and stoichiometric $\mathrm{UO}_{2}$ come from the works of Konings et al. [15], the SGTE database [16], and Guéneau et al. [12] respectively. The compound energy formalism (CEF) sublattice model developed in [12] was used to determine the activity of $\mathrm{UO}_{2}$ as a function of $p_{O_{2}}$.

As pointed out in [1], $K_{e q}$ is the cause of the differences in the curves given in Fig. 5. Fig. 6 compares the $a_{U_{2}}$ versus $p_{O_{2}}$ for the three different models evaluated in this work and shows good agreement between them. In fact, when an identical $K_{e q}$ is used in Eqn. 8, nearly identical computed $p_{\mathrm{UO}_{3}}$ values are obtained regardless of which $a_{\mathrm{UO}_{2}}$ to $p_{\mathrm{O}_{2}}$ relation is operative. Olander [1] reviewed the available thermodynamic data and recommended $K_{e q}$ based on transpiration measurements of $\mathrm{UO}_{3}(\mathrm{~g})$ over $\mathrm{U}_{3} \mathrm{O}_{8}$ determined by Kirkorkian [2]. Fig. 7 shows that the Calphad and Kirkorkian et al. [2] $K_{e q}$ plots with temperature are in very good agreement.

\section{Conclusions}

This work adds $p_{U_{3}}$ measurements in equilibrium with fluorite structure $\mathrm{UO}_{2+\mathrm{x}}$ to those characterizing it over $\mathrm{U}_{3} \mathrm{O}_{8}[2 ; 10 ; 17]$ and illustrates the usefulness of the transpiration coupled TGA technique for determining equilibrium vapor pressures of nonstoichiometric oxides. The experimental results from this work give more certainty to the Gibbs energy of reaction for Eqn. 7 from either $[12 ; 15 ; 16]$ and [2], which are practically equivalent, and can be combined with an appropriate model for $\mathrm{UO}_{2+\mathrm{x}}$, like those from $[3 ; 12 ; 14]$, for a thermodynamic description of the equilibrium vapors over $\mathrm{UO}_{2+\mathrm{x}}$. This facilitates experimentally characterizing $\mathrm{UO}_{2}(\mathrm{OH})_{2}$ formation from $\mathrm{UO}_{2+\mathrm{x}}$ reaction with pressurized water or steam and aids in better understanding fuel behavior under severe accident conditions.

\section{Acknowledgements}

The author would like to thank Dr. Nathan S. Jacobson of NASA Glenn Research Center for invaluable guidance and helpful comments. The author would also like to thank Wally Porter and Cristian Contescu of Oak Ridge National Laboratory. The work was supported by the US Department of Energy, Office of Nuclear Energy Fuel Cycle Technology Program. 


\section{References}

[1] D. Olander, J. Nucl. Mater. 270 (1999) 187-193.

[2] O. Krikorian, B. Ebbinghaus, M.G. Adamson, A.S. Fontes Jr, D. Fleming, Experimental studies and thermodynamic modelling of volatilities of uranium, plutonium, and americium from their oxides and from their oxides interacted with ash, Lawrence Livermore National Lab., CA (United States), 1993.

[3] P. Blackburn, J. Nucl. Mater. 46 (1973) 244-252.

[4] B. Lewis, B. Corse, W. Thompson, M. Kaye, F. Iglesias, P. Elder, R. Dickson, Z. Liu, J. Nucl. Mater. 252 (1998) 235-256.

[5] V. Ozrin, Nuclear Safety Institute of the Russian Academy of Sciences NSI-SARR-43-96 (1996).

[6] U. Merten, W. Bell, The Characterization of High-Temperature Vapors. in: J.L. Margrave, (Ed.), Wiley, New York, 1967.

[7] M. Ali, R. Mishra, A.S. Kerkar, S.R. Bharadwaj, D. Das, J. Nucl. Mater. 301 (2002) 183186.

[8] R. Pankajavalli, S. Anthonysamy, K. Ananthasivan, P.V. Rao, J. Nucl. Mater. 362 (2007) 128-131.

[9] R. Viswanathan, T.L. Narasimhan, S. Nalini, The Journal of Physical Chemistry B 113 (2009) 8362-8368.

[10] R. Ackermann, R. Thorn, C. Alexander, M. Tetenbaum, The Journal of Physical Chemistry 64 (1960) 350-355.

[11] D.R. Olander, Fundamental aspects of nuclear reactor fuel elements, California Univ., Berkeley (USA). Dept. of Nuclear Engineering, 1976.

[12] C. Guéneau, N. Dupin, B. Sundman, C. Martial, J.C. Dumas, S. Gosse, S. Chatain, F. De Bruycker, D. Manara, R.J.M. Konings, J. Nucl. Mater. 419 (2011) 145-167.

[13] J.R. Taylor, An introduction to error analysis: the study of uncertainties in physical measurements, University science books, 1997.

[14] T.B. Lindemer, T.M. Besmann, J. Nucl. Mater. 130 (1985) 473-488.

[15] R.J. Konings, O. Beneš, J. Phys. Chem. Ref. Data 39 (2010) 043102.

[16] SGTE Substances Database Version 2.

[17] S. Dharwadkar, S. Tripathi, M. Karkhanavala, M. Chandrasekharaiah, Thermodynamic properties of gaseous uranium hydroxide, Symposium on the thermodynamics of nuclear materials, International Atomic Energy Agency, Vienna (Austria), 1975, pp. 455-465. 
Table 1. Experimental $p_{U O_{3}}$ pressures with standard uncertainty $u\left(p_{U O_{3}}\right)$ over single phase $\mathrm{UO}_{2+x}$ or $\mathrm{U}_{3} \mathrm{O}_{8}$ as a function of temperature, $T$, and $p_{O_{2}}$ with standard uncertainty $u\left(p_{O_{2}}\right)^{a, b}$

\begin{tabular}{cccccc}
\hline$T / \mathrm{K}$ & $p_{\mathrm{O}_{2}} / \mathrm{atm}$ & $u\left(p_{\mathrm{O}_{2}}\right) / \mathrm{atm}$ & $p_{U O_{3}} / \mathrm{atm}$ & $u\left(p_{U O_{3}}\right) / \mathrm{atm}$ & $\begin{array}{c}\text { Phases present } \\
\text { (calc.) }\end{array}$ \\
\hline 1573 & $1.00 \times 10^{-3}$ & $2.37 \times 10^{-4}$ & $3.78 \times 10^{-6}$ & $4.03 \times 10^{-7}$ & $\mathrm{UO}_{2+\mathrm{x}}$ \\
1573 & $1.00 \times 10^{-2}$ & $1.83 \times 10^{-4}$ & $9.12 \times 10^{-6}$ & $4.03 \times 10^{-7}$ & $\mathrm{U}_{3} \mathrm{O}_{8}$ \\
1573 & $2.00 \times 10^{-2}$ & $2.00 \times 10^{-4}$ & $1.18 \times 10^{-5}$ & $4.03 \times 10^{-7}$ & $\mathrm{U}_{3} \mathrm{O}_{8}$ \\
1773 & $1.00 \times 10^{-3}$ & $2.37 \times 10^{-4}$ & $3.47 \times 10^{-5}$ & $4.03 \times 10^{-7}$ & $\mathrm{UO}_{2+\mathrm{x}}$ \\
1773 & $1.00 \times 10^{-2}$ & $1.83 \times 10^{-4}$ & $1.10 \times 10^{-4}$ & $4.03 \times 10^{-7}$ & $\mathrm{UO}_{2+\mathrm{x}}$ \\
1773 & $2.00 \times 10^{-2}$ & $2.00 \times 10^{-4}$ & $1.44 \times 10^{-4}$ & $4.03 \times 10^{-7}$ & $\mathrm{UO}_{2+\mathrm{x}}$ \\
\hline
\end{tabular}

${ }^{\text {a }}$ Standard uncertainties $u$ are $u(T)=0.05 \mathrm{~K}$ and $u\left(P_{\text {sys }}\right)=0.03 \mathrm{~atm}$.

${ }^{\mathrm{b}} 1 \mathrm{~atm}=101,325 \mathrm{~Pa}$ 
Table 2. Sources of experimental uncertainty.

\begin{tabular}{lll}
\hline Source & Manufacturer & Uncertainty \\
\hline Ar-2.00\% $\mathrm{O}_{2}$ composition & Air Liquide & $\pm 1 \%$ of reported composition \\
Ar-4.01\% $\mathrm{H}_{2}$ composition & Air Liquide & $\pm 2 \%$ of reported composition \\
Mixed gas flow rate & Environics & $\pm 0.5 \%$ of the flow \\
Thermocouple & Netzsch & $\pm 0.05 \mathrm{~K}$ \\
\hline
\end{tabular}


Table 3. Reported purity of standards provided by Netzsch Instruments used for the TGA thermocouple calibration.

\begin{tabular}{cc}
\hline Material & Purity $(\%)$ \\
\hline $\mathrm{Ni}$ & 99.99 \\
$\mathrm{Al}$ & 99.999 \\
$\mathrm{Zn}$ & 99.999 \\
$\mathrm{Au}$ & 99.999 \\
$\mathrm{Ag}$ & 99.99
\end{tabular}




\section{List of Figures}

Figure 1. (a) Phase diagram of the integral U-O binary system calculated using the Calphad assessment of Guéneau et al. (b) Section in the vicinity of the $\mathrm{UO}_{2 \pm x}$ solution. The symbols show the calculated compositions and the corresponding $\log p_{O_{2}}$ in atm for the transpiration measurements from this work.

Figure 2. Simplified diagram of the simultaneous thermal analyzer (STA) used in this study.

Figure 3. (a) Mass loss and (b) $\mathrm{UO}_{3}$ partial pressure versus flow rate at $1573 \mathrm{~K}$.

Figure 4. (a) Mass loss versus and (b) $\mathrm{UO}_{3}$ partial pressure versus flow rate at $1773 \mathrm{~K}$.

Figure 5. Calculated (lines) $\mathrm{UO}_{3}$ partial pressure versus experimental measurements (symbols) at (a) $1573 \mathrm{~K}$ and (b) $1773(\mathrm{~K})$

Figure 6. Activity of $\mathrm{UO}_{2}$ in $\mathrm{UO}_{2+\mathrm{x}}$ as a function of oxygen pressure at (a) $1573 \mathrm{~K}$ and (b) 1773 $\mathrm{K}$ from various models.

Figure 7. Equilibrium constant $\left(\mathrm{K}_{\mathrm{eq}}\right)$ versus temperature for the reaction given by Eqn. 7. The $\mathrm{K}_{\mathrm{eq}}$ line from Kirkorkian et al. and that computed using the Calphad models are nearly identical. 
(a)

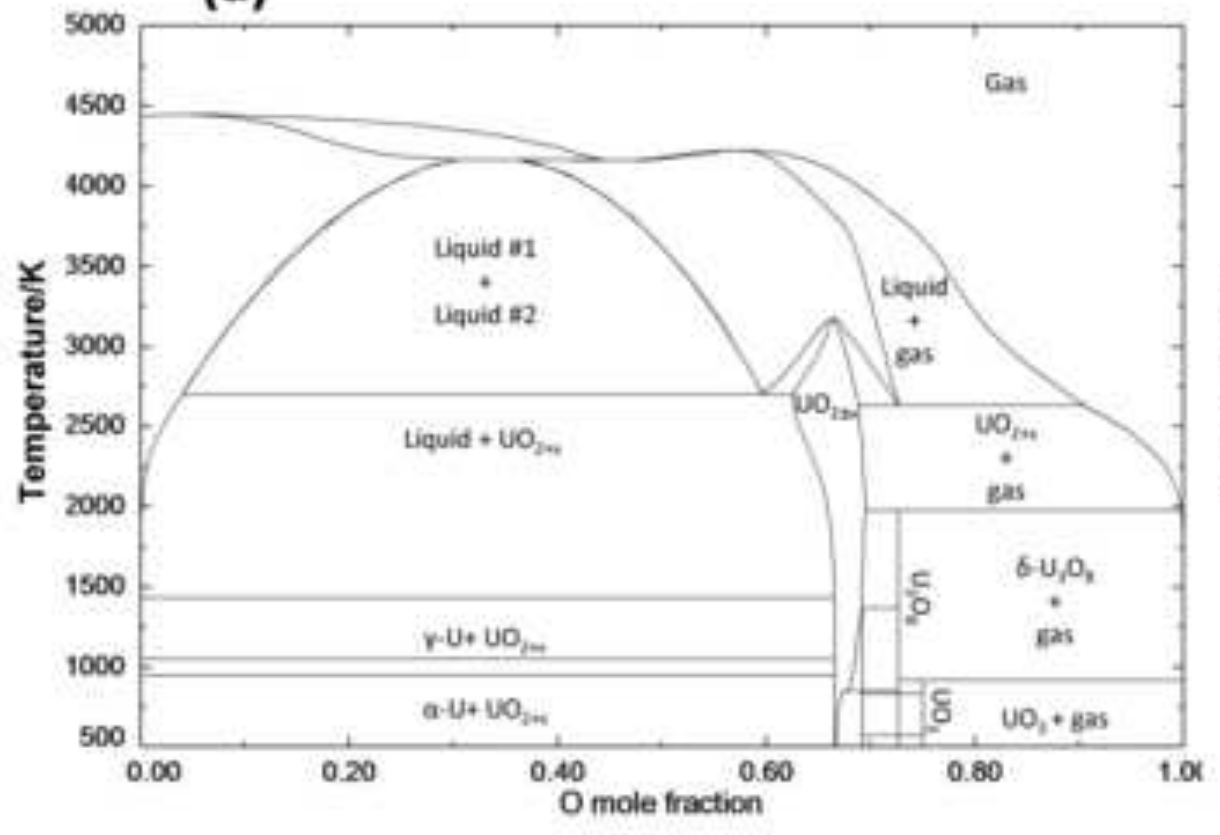

(b)

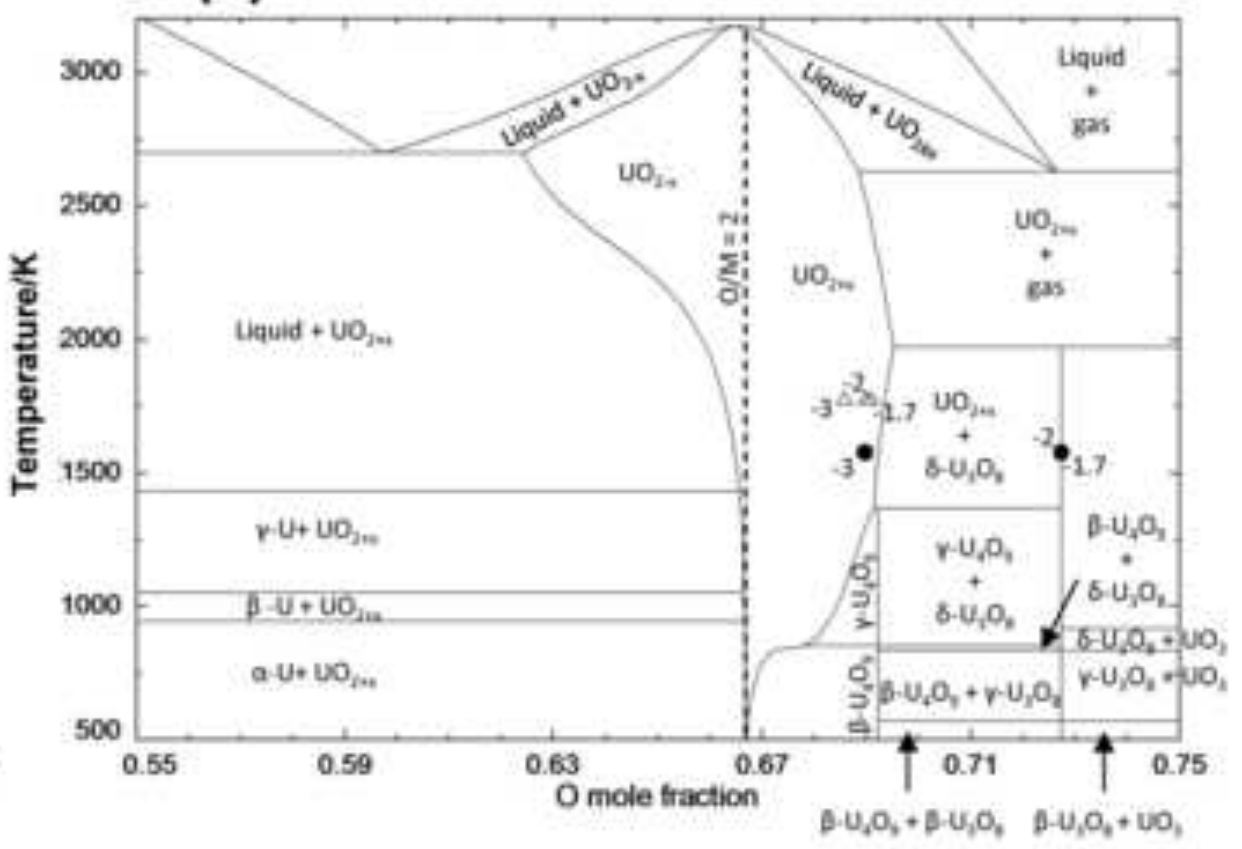




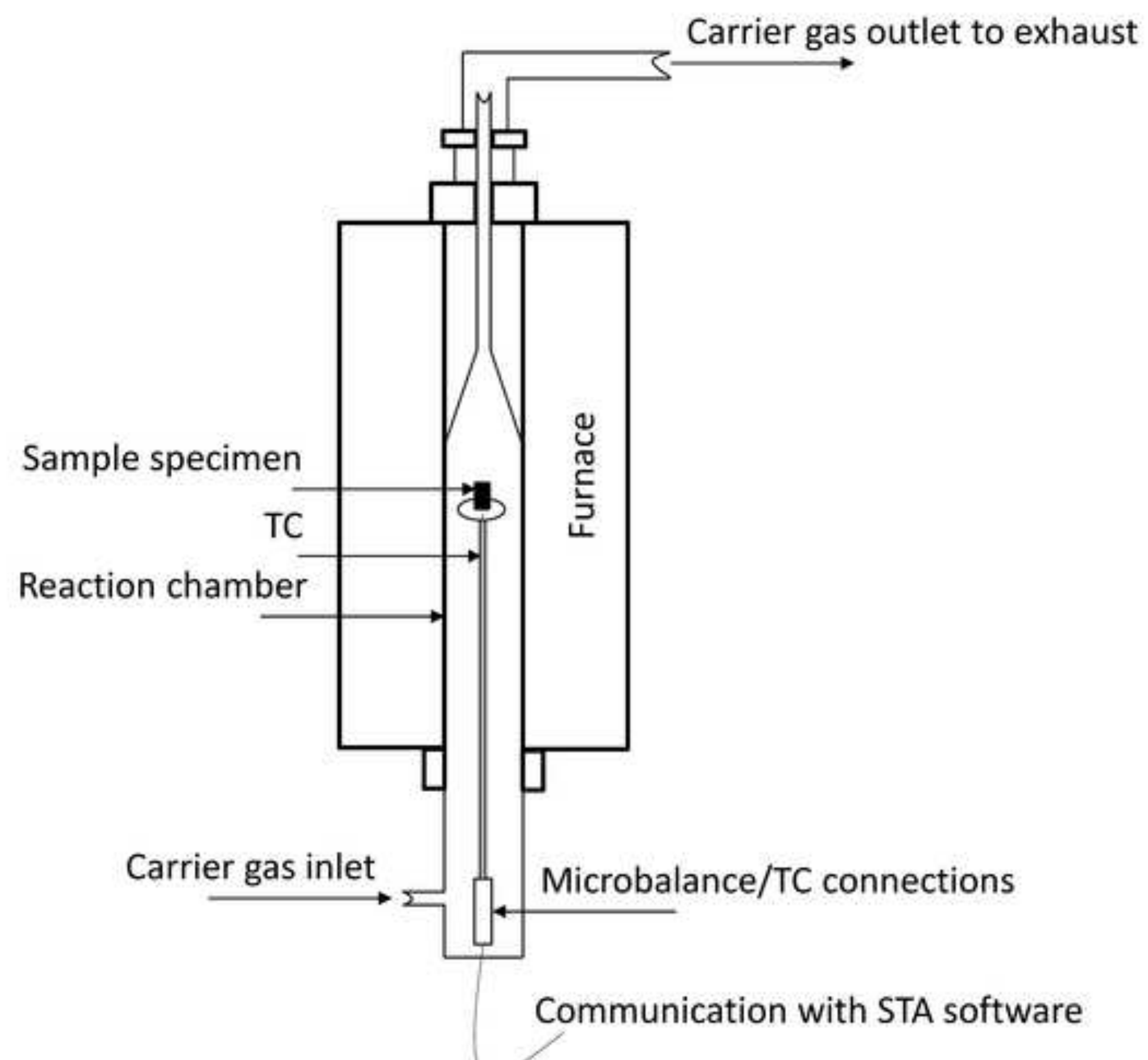




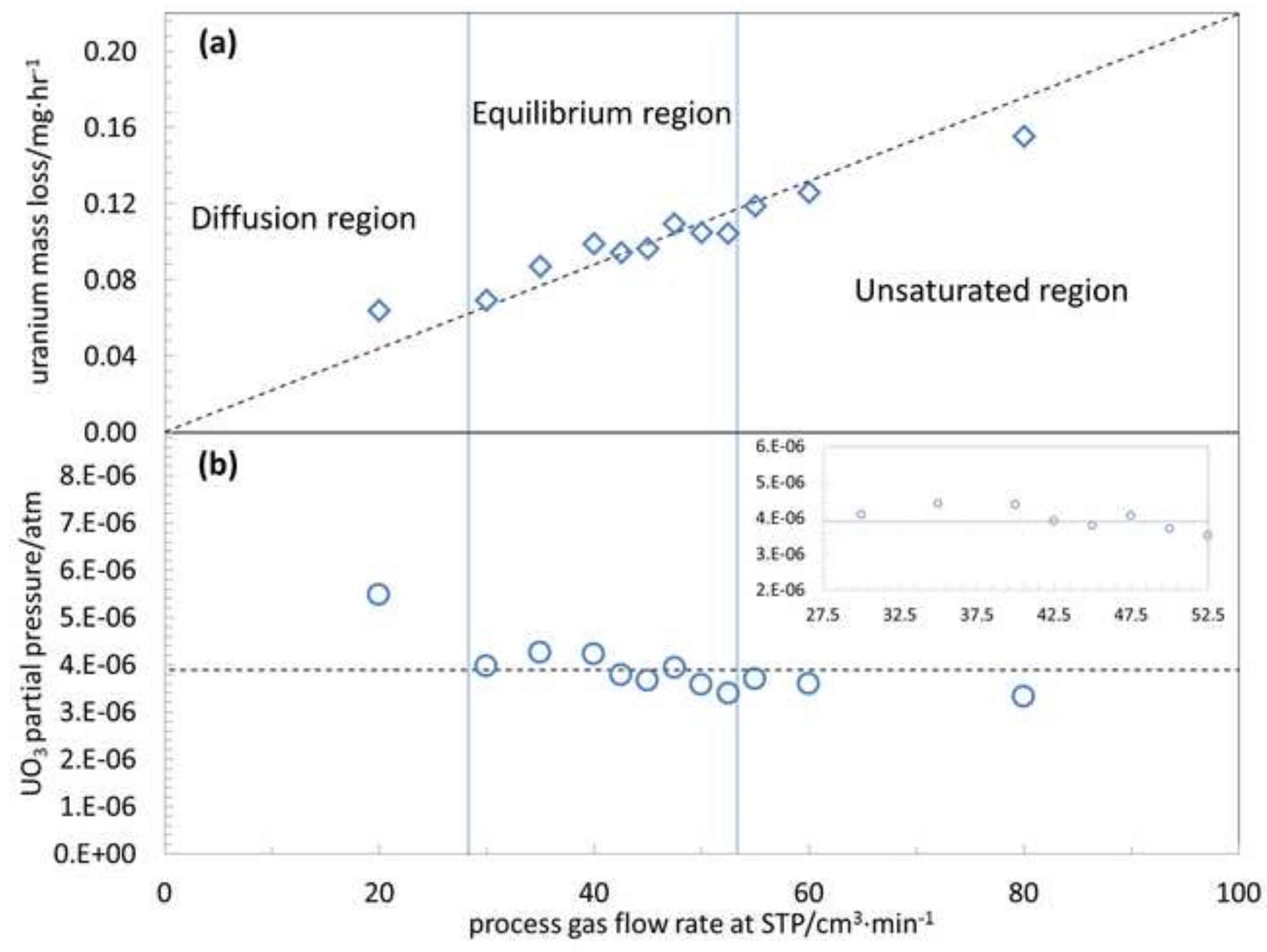




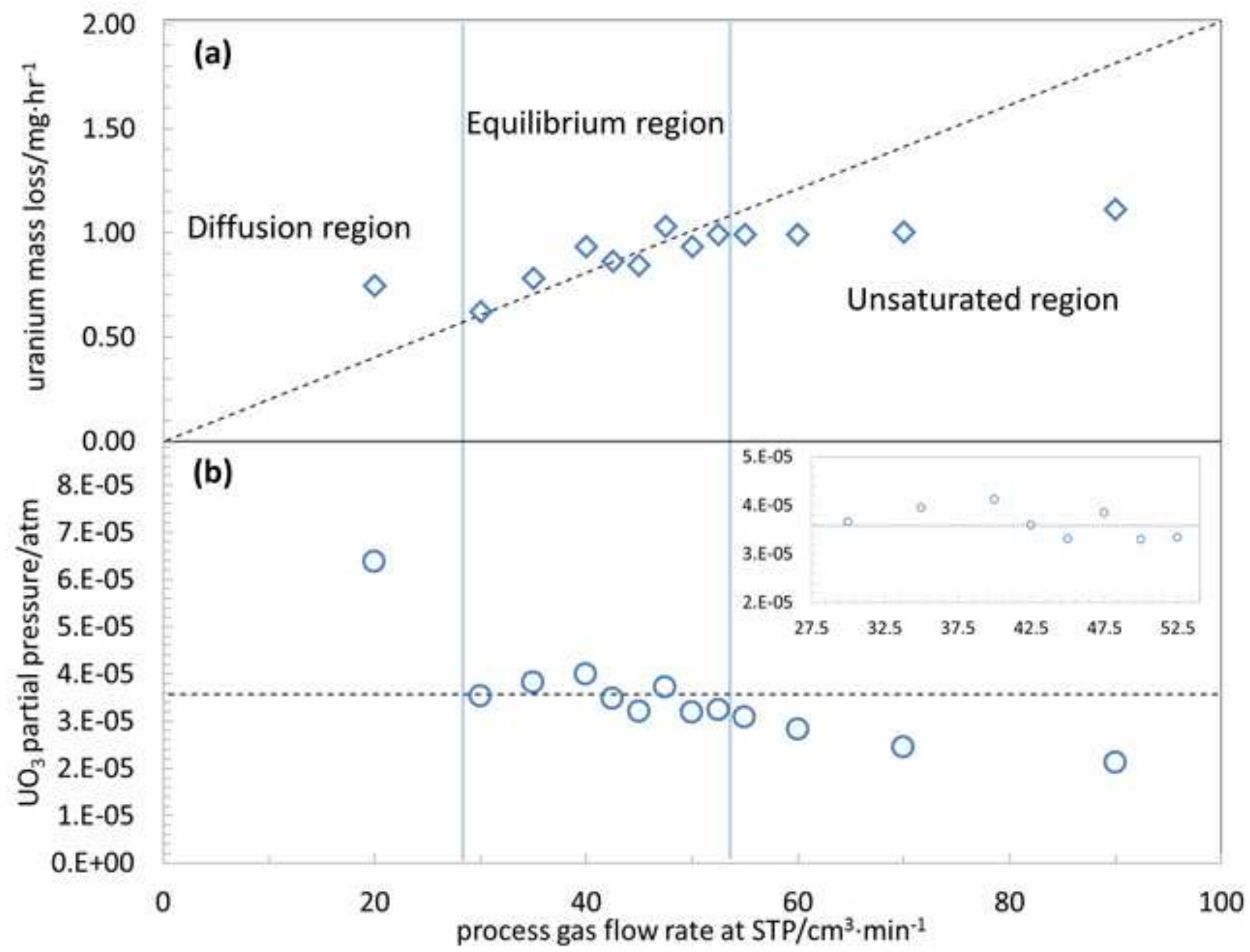




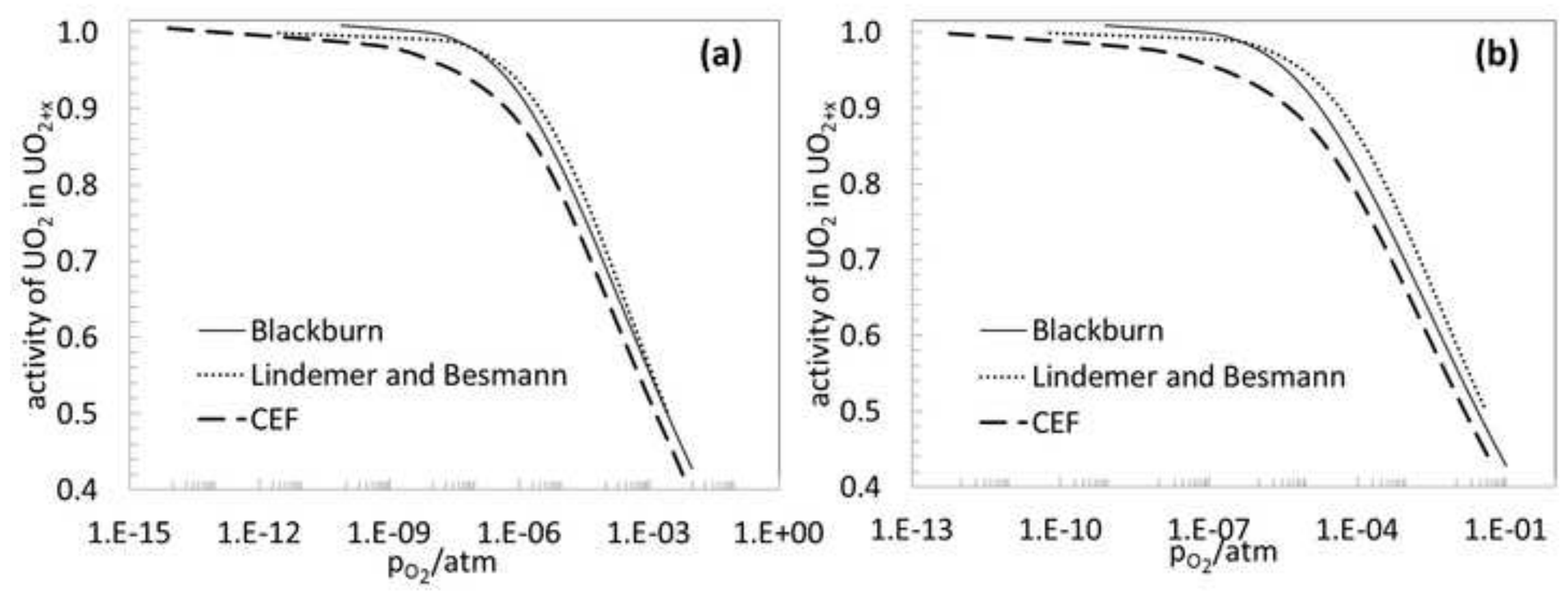




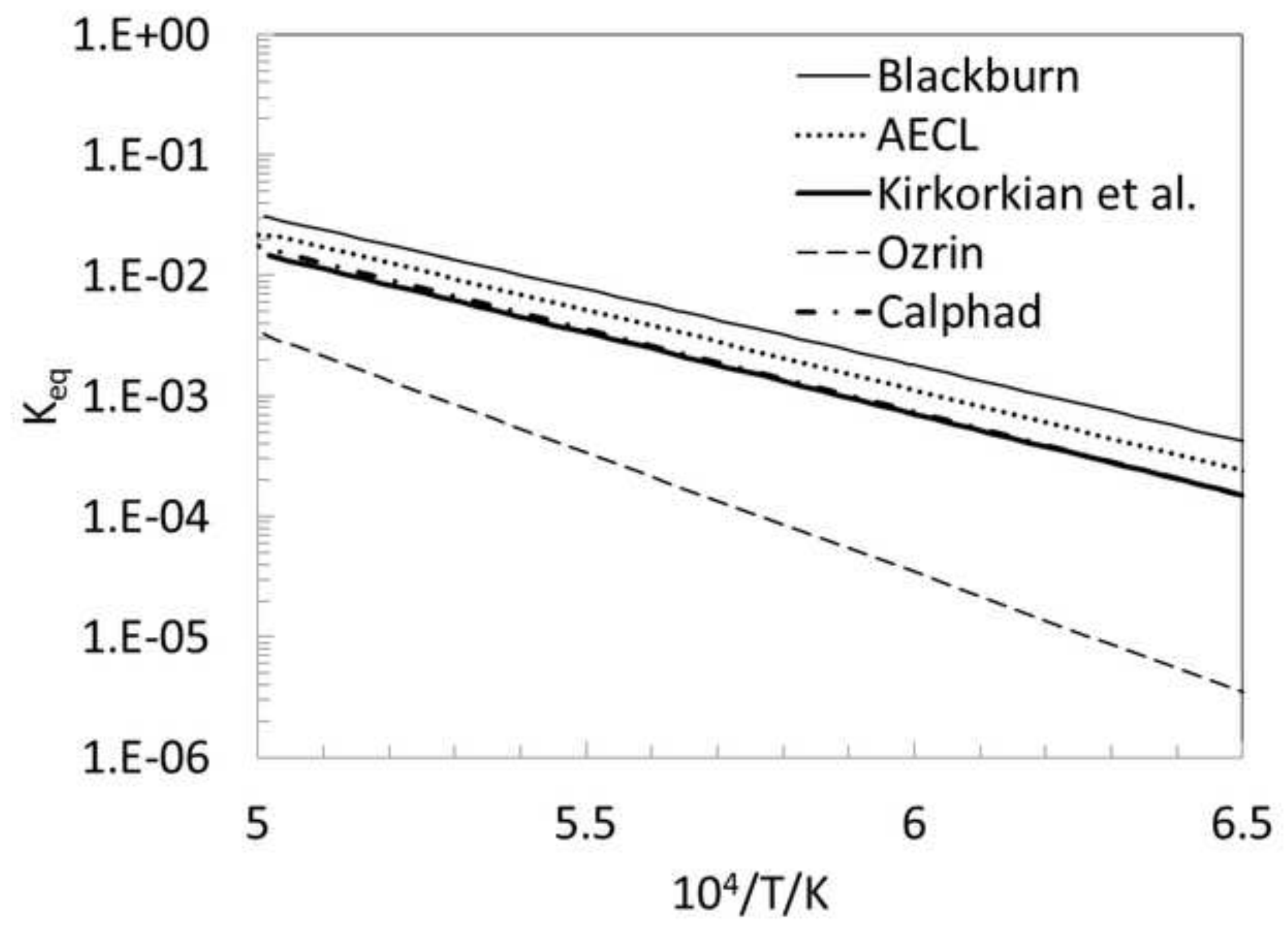



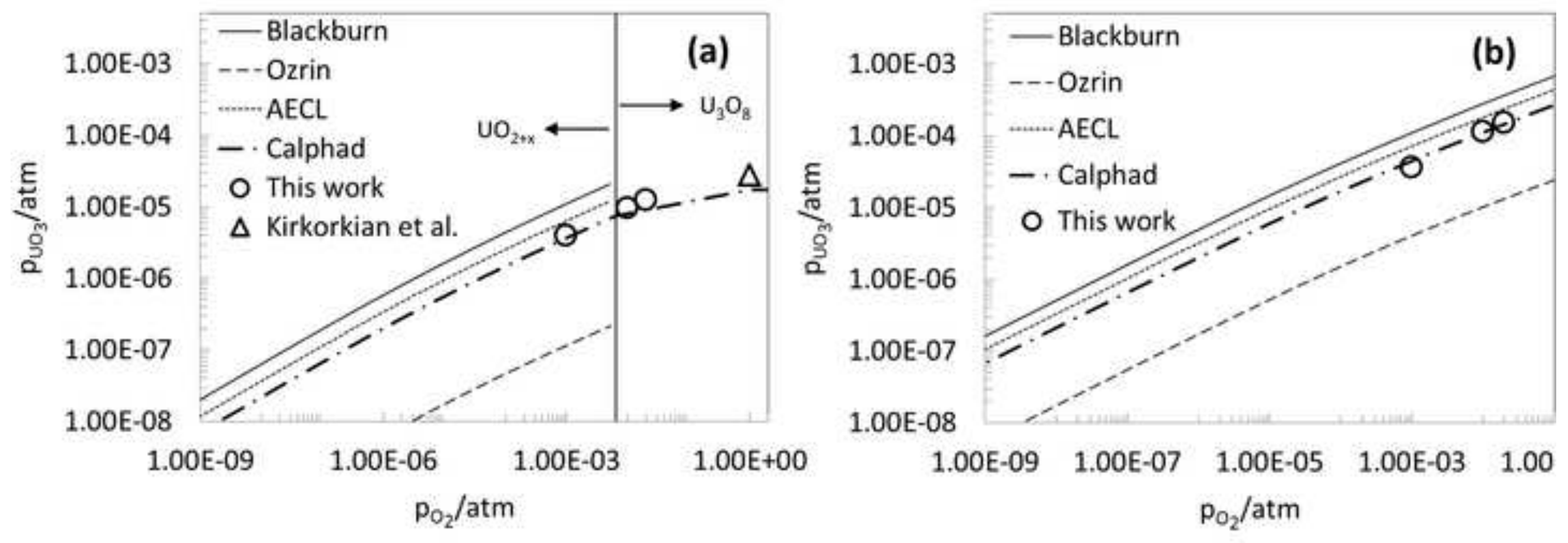